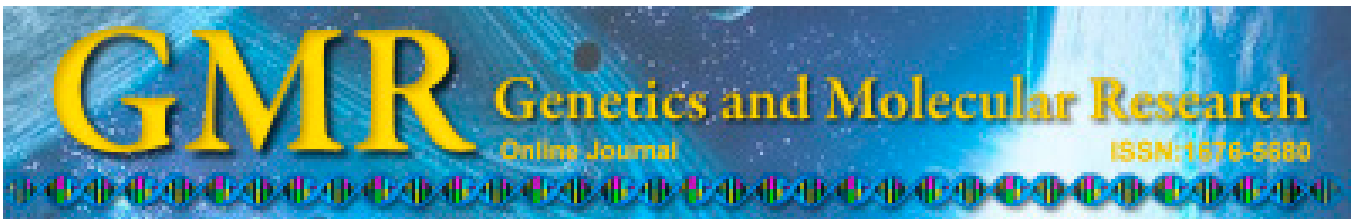

\title{
Polymorphisms in a myostatin gene and associations with growth in a hybrid of Culter alburnus and Ancherythroculter nigrocauda
}

\author{
L. Cheng ${ }^{1}$ and Y.H. Sun ${ }^{2,3}$
}

${ }^{1}$ Key Laboratory of Adolescent Cyberpsychology and Behavior, Ministry of Education and School of Psychology, Central China Normal University, Wuhan, China

${ }^{2}$ Wuhan Aquaculture Science Research Institute, Wuhan, China

${ }^{3}$ Wuhan Academy of Agricultural Science Technology, Wuhan, China

Corresponding author: Y.H Sun

E-mail: sunyanhong0830@126.com

Genet. Mol. Res. 14 (2): 5615-5620 (2015)

Received August 5, 2014

Accepted March 6, 2015

Published May 25, 2015

DOI http://dx.doi.org/10.4238/2015.May.25.13

\begin{abstract}
Myostatin (MSTN) is a member of the transforming growth factor- $\beta$ superfamily that negatively regulates skeletal muscle development and growth. In the present study, partial genomic fragments of MSTN were screened for single nucleotide polymorphisms (SNPs) in a hybrid of Culter alburnus (P) x Ancherythroculter nigrocauda $\left({ }^{A}\right)$ individuals from a commercial hatchery population, and two non-synonymous SNPs (c.6T $>C$ and c. $162 \mathrm{G}>\mathrm{A}$ ) and two synonymous SNPs (c. $152 \mathrm{G}>\mathrm{A}$ and c. $155 \mathrm{G}>\mathrm{A}$ ) in exon 2 were identified. The two non-synonymous SNPs caused an amino acid change, from Ser to Pro and from Val to Ile, respectively. Genotyping by the direct sequencing of polymerase chain reaction products for these four SNPs was conducted in 190 individuals from the commercial hatchery population. Association analysis showed that one non-synonymous SNP (c.6T $>$ C) in exon 2 was significantly associated with total length, body length, body height, head length, and body weight. Haplotype analyses re-
\end{abstract}


vealed that the haplotype combination $\mathrm{H} 1 \mathrm{H} 3$ exhibited the best growth performance. Our results demonstrate that some of the SNPs in MSTN may have positive effects on growth, and suggest that MSTN could be a candidate gene for marker-assisted selection in C. alburnus and $A$. nigrocauda.

Key words: Myostatin (MSTN); Association analysis; Growth traits; INTRODUCTION Single nucleotide polymorphisms

Culter alburnus (Cypriniformes, Cyprinidae, Culterinae, Culter) is a freshwater carnivorous fish species that is widely distributed in China. Owing to its large size, fast growth, and excellent taste, it has become one of the most popular fish species in Chinese aquatic markets (Cao et al., 2011). However, this species has unwanted characteristics, such as sexual ferocity, high-protein feed requirements, is not easy to transport live, and can exhibit a strong stress reaction. Ancherythroculter nigrocauda (Cypriniformes, Cyprinidae, Culterinae, Ancherythroculter) has a high economic value and lives in the upper reaches of the Yangtze River, and has a more gentle temperament, low-protein feed requirements, and is easier to transport (Xiong et al., 2006). For these reasons, we developed a new genetic strain by crossing a female $C$. alburnus with a male $A$. nigrocauda, in order to improve the breeding traits of $C$. alburnus females and $A$. nigrocauda males.

Myostatin (MSTN), which is also called GDF-8, belongs to the TGF- $\beta$ superfamily. It is a growth factor that is mainly expressed in muscle, and regulates development and growth by inhibiting cell cycle progression. McPherron et al. (1997) found that MSTN negatively regulates the growth of skeletal muscle. Because of its role in regulating muscle development and growth, MSTN has been selected as an important candidate gene for studies on productivity, growth, and performance in domestic animals, including pigs (Yu et al., 2007), sheep (Boman et al., 2009), chickens (Zhang et al., 2011), rabbits (Fontanesi et al., 2011), and aquaculture species, such as the bay scallop (Argopecten iradians) (Guo et al., 2011). MSTN may be an important target gene for growth improvements in cultured fish (Tang et al., 2010). To date, no studies on MSTN polymorphisms and their possible associations with growth traits have been reported in C. alburnus or A. nigrocauda. In the present study, novel SNPs were identified in the MSTN of a commercial hatchery population. The aim of this study was to explore the association between MSTN polymorphisms and the growth traits of the cultured population. The results of this study should be useful in evaluating MSTN as a candidate gene for markerassisted selection (MAS) for growth in C. alburnus and A. nigrocauda.

\section{MATERIAL AND METHODS}

\section{Populations and phenotypic measurements}

A commercially cultured population was generated by crossing 10 males and 10 females that were hormonally induced during the spawning season, at the Wuhan Aquaculture Science Research Institute, Hubei Province, China. Juveniles were raised in the same pond until 18 months post-hatching. Individuals were randomly sampled and the total length, body length, body height, head length, and body weight were measured. The protocol for the proj- 
ect was approved by the Institutional Animal Care and Use Committee of the Central China Normal University.

\section{Genotyping and statistical analysis}

Based on the complete sequence for the C. alburnus MSTN (GenBank accession number KC583257.1), a pair of primers (forward, 5'-GGTTCGTATCTTAGCCAATCT-3'; reverse, 5'-AACTCACCAGTCCATCCTCTC-3') was designed to amplify an 803-bp fragment of genomic DNA. The obtained sequences included partial intron 1 and total exon 2, corresponding to nt 703-1505 of the GenBank sequence KC583257.1. The discovery and genotyping of the SNPs in MSTN were performed by direct sequencing of the polymerase chain reaction products. Association analyses between the MSTN genotypes and the growth traits were performed using a general linear model with the SPSS 13.0 software, which was given as:

$$
\mathrm{Y}=\mathrm{u}+\mathrm{G}+\mathrm{e}
$$

(Equation 1)

where $Y$ is the phenotypic value of each trait, $u$ is the mean population value of four growth traits, $G$ is the fixed effects of the genotypes of each SNP, and $e$ is the random error. The Popgene 32 software was used to test allelic and genotypic frequencies and the Hardy-Weinberg equilibrium (HWE), and to calculate the observed heterozygosity $\left(H_{\mathrm{O}}\right)$ and the expected heterozygosity $\left(H_{\mathrm{E}}\right)$.

\section{RESULTS AND DISCUSSION}

In total, 190 individuals were sequenced and two non-synonymous SNPs (c.6T $>\mathrm{C}$ and c. $162 \mathrm{G}>\mathrm{A}$ ) and two synonymous SNPs (c.152G $>$ A and c.155G $>$ A) were identified in exon 2 . The two non-synonymous SNPs resulted in a change in amino acids (Ser to Pro and Val to Ile). The $H_{\mathrm{O}}$ and $H_{\mathrm{E}}$ ranged from 0.021 to 0.858 , and from 0.021 to 0.491 , respectively. One locus $($ c.6T $>$ C) significantly deviated from the $\operatorname{HWE}(\mathrm{P}<0.05$; Table 1$)$.

\begin{tabular}{|c|c|c|c|c|c|c|c|c|c|}
\hline \multirow{2}{*}{$\begin{array}{l}\text { Locus } \\
\text { c.6T }>\mathrm{C}\end{array}$} & \multirow{2}{*}{ No. of animals } & \multicolumn{3}{|c|}{ Genotype frequencies (\%) } & \multicolumn{2}{|c|}{ Allele frequencies (\%) } & \multirow{2}{*}{$\begin{array}{c}H_{\mathrm{O}} \\
0.858\end{array}$} & \multirow{2}{*}{$\begin{array}{c}H_{\mathrm{E}} \\
0.491\end{array}$} & \multirow{2}{*}{$\begin{array}{l}\mathrm{HWE} \\
0.00 \mathrm{C}\end{array}$} \\
\hline & & TT & $\mathrm{CT}$ & $\mathrm{CC}$ & $\mathrm{T}$ & $\mathrm{C}$ & & & \\
\hline & 190 & 14.2 & 85.8 & 0 & 57.1 & 42.9 & & & \\
\hline \multirow[t]{2}{*}{ c. $152 \mathrm{G}>\mathrm{A}$} & & GG & GA & AA & G & A & 0.100 & 0.095 & 1.000 \\
\hline & 190 & 90.0 & 10.0 & 0 & 95.0 & 5.0 & & & \\
\hline \multirow[t]{2}{*}{ c. $155 \mathrm{G}>\mathrm{A}$} & & GG & GA & AA & G & A & 0.058 & 0.056 & 1.000 \\
\hline & 190 & 94.2 & 5.8 & 0 & 97.1 & 2.9 & & & \\
\hline \multirow[t]{2}{*}{ c. $162 \mathrm{G}>\mathrm{A}$} & & GG & GA & AA & $\mathrm{G}$ & A & 0.021 & 0.021 & 1.000 \\
\hline & 190 & 97.9 & 2.1 & 0 & 98.9 & 1.1 & & & \\
\hline
\end{tabular}

$H_{\mathrm{O}}=$ observed heterozygosity; $H_{\mathrm{E}}=$ expected heterozygosity; HWE = Hardy-Weinberg equilibrium.

In the experimental population, the homozygosis mutational genotype was not detected for all four SNPs. The association analyses between the genotypes of the four SNPs and the five growth traits indicated that the non-synonymous SNP c.6T $>\mathrm{C}$ was significantly associated with all five traits. For SNP c.6T $>$ C, the T allele frequency was higher than the $\mathrm{C}$ 
allele frequency (Table 1), and fish with the TC genotype were significantly more associated with all five traits than were fish with the TT genotype $(\mathrm{P}<0.01$; Table 2$)$.

\begin{tabular}{|c|c|c|c|c|c|c|}
\hline Genotypes & No. of animals & BW (g) & $\mathrm{TL}(\mathrm{cm})$ & $\mathrm{BL}(\mathrm{cm})$ & $\mathrm{BH}(\mathrm{cm})$ & $\mathrm{HL}(\mathrm{cm})$ \\
\hline TT & 27 & $370.68 \pm 123.49^{A}$ & $33.99 \pm 3.39^{\mathrm{A}}$ & $29.48 \pm 3.25^{\mathrm{A}}$ & $7.19 \pm 1.00^{\mathrm{A}}$ & $6.06 \pm 0.58^{\mathrm{A}}$ \\
\hline CT & 163 & $447.86 \pm 112.77^{\mathrm{B}}$ & $36.23 \pm 3.01^{\mathrm{B}}$ & $31.62 \pm 2.70^{\mathrm{B}}$ & $7.69 \pm 0.79^{\mathrm{B}}$ & $6.36 \pm 0.51^{\mathrm{B}}$ \\
\hline$P$ value & & 0.001 & 0.001 & 0.004 & 0.006 & 0.004 \\
\hline
\end{tabular}

$\mathrm{BW}=$ body weight; $\mathrm{TL}=$ total length; $\mathrm{BL}=$ body length; $\mathrm{BH}=$ body height; $\mathrm{HL}=$ head length. The different superscript letters within a column mean significant difference $(\mathrm{P}<0.01)$.

These results indicate that $\mathrm{C}$ alleles had a positive effect on growth in the tested population. The other three SNPs had no significant association with any of the five growth traits. Five haplotype combinations were found in the population, based on the four SNP loci. Four major haplotype combinations, which included 186 individuals, were used for the association analyses; one haplotype combination was excluded because of a low number of individuals. For the five growth traits, individuals with haplotype H1H3 exhibited the best growth performance $(\mathrm{P}<0.05$ or 0.01 ; Table 3$)$.

\begin{tabular}{|c|c|c|c|c|c|c|}
\hline Haplotype combinations & No. of animals & BW (g) & $\mathrm{TL}(\mathrm{cm})$ & $\mathrm{BL}(\mathrm{cm})$ & $\mathrm{BH}(\mathrm{cm})$ & $\mathrm{HL}(\mathrm{cm})$ \\
\hline $\mathrm{H} 1 \mathrm{H} 2 \mathrm{TGGG} / \mathrm{CGGG}$ & 129 & $446.37 \pm 115.89^{b}$ & $36.17 \pm 3.04^{\mathrm{b}}$ & $31.53 \pm 2.70^{b}$ & $7.69 \pm 0.81^{b}$ & $6.38 \pm 0.51^{\mathrm{b}}$ \\
\hline H1H1TGGG/TGGG & 27 & $370.68 \pm 123.49^{\mathrm{a}}$ & $33.99 \pm 3.39^{\mathrm{a}}$ & $29.48 \pm 3.25^{\mathrm{a}}$ & $7.19 \pm 1.01^{\mathrm{a}}$ & $6.06 \pm 0.58^{\mathrm{a}}$ \\
\hline H1H3TGGG/CAGG & 19 & $472.92 \pm 87.84^{b}$ & $36.84 \pm 2.68^{b}$ & $32.41 \pm 2.31^{\mathrm{b}}$ & $7.78 \pm 0.53^{b}$ & $6.30 \pm 0.54^{b}$ \\
\hline H1H4TGGG/CGAG & 11 & $455.05 \pm 105.42^{b}$ & $36.61 \pm 3.09^{b}$ & $32.16 \pm 2.81^{\mathrm{b}}$ & $7.73 \pm 0.76^{b}$ & $6.41 \pm 0.44^{\mathrm{b}}$ \\
\hline$P$ value & & 0.011 & 0.023 & 0.025 & 0.019 & 0.022 \\
\hline
\end{tabular}

$\mathrm{BW}=$ body weight; $\mathrm{TL}=$ total length; $\mathrm{BL}=$ body length; $\mathrm{BH}=$ body height; $\mathrm{HL}=$ head length. The different superscript letters within a column mean significant difference $(P<0.05)$. The same superscript letters within a column mean no significant difference $(\mathrm{P}>0.05)$.

Although the MSTN of C. alburnus has been published in GenBank, there is no report of the effects of the MSTN SNPs on growth traits. Our study is the first examination of the four MSTN SNPs in an hybrid C. alburnus, and is also the first report of a significant association between these polymorphisms and growth traits in a commercial population of C. alburnus. Our results show that an SNP in exon 2 of the MSTN may have had a positive impact on the growth of hybrid Culter. Fish with TC genotypes exhibited a superior growth performance, and may be kept for further breeding studies. We assume that this mutation changed the protein structure, which consequently affected growth performance. Many studies have shown that SNPs in MSTN affect the growth performance of aquaculture animals. Wang et al. (2010) found that one non-synonymous SNP in MSTN exon 2 is significantly associated with growth traits, and can facilitate muscle growth in the Zhikong scallop (Chlamys farreri). In addition, Liu et al. (2012) identified one SNP in the 3'-regulatory region of the MSTN that is significantly associated with three growth traits (body weight, total length, and body length) in the bighead carp (Hypophthalmichthys nobilis). However, a single locus may only provide limited information about the association between SNP polymorphisms and economic traits. 
Some association studies had demonstrated that if the genotypes of two or more SNPs were linked, they would be more informative (He et al., 2008, 2011). Our analyses shows that fish with $\mathrm{H} 1 \mathrm{H} 3$ exhibited a much better growth performance than those without $\mathrm{H} 1 \mathrm{H} 3$, possibly because of the inclusion of favorable $\mathrm{C}$ and $\mathrm{A}$ alleles, and these individuals may be kept for further breeding studies; allelic interactions and the gene expressions of different SNPs on growth traits will be further studied. The advantage of genic SNP markers is their location in the DNA regions that code proteins for the somatotropic axis, meaning that they are more likely to be near quantitative trait loci (QTLs), which affect growth (Tao and Boulding, 2003; Lei et al., 2007). The use of molecular markers linked to QTLs can provide an accurate estimation of breeding values for animals prior to obtaining accurate phenotypic information, and could be used in MAS (Hayes et al., 2007). Our results show that the SNP in the MSTN coding region was an important factor in the variance of growth traits; therefore, it could act as a candidate gene for C. alburnus breeding.

In the present study, four novel SNPs were identified in a hybrid of C. alburnus (ㅇ) $\mathrm{x}$ A. nigrocauda $\left({ }^{\lambda}\right) \mathrm{MSTN}$, and one non-synonymous SNP in exon 2 was significantly associated with five growth traits. Fish with one of the combined haplotypes $(\mathrm{H} 1 \mathrm{H} 3)$ also exhibited better growth performance. This study provides further evidence of associations between MSTN polymorphisms and growth traits in a hybrid, and these results would be valuable for the candidate gene approach and the use of MSTN for MAS in C. alburnus and A. nigrocauda.

\section{ACKNOWLEDGMENTS}

Research supported by grants from the National Science Foundation of China (\#31300914 and \#31402296), the China Postdoctoral Science Foundation (\#2013M531719 and \#2014T70716), the Wuhan Chenguang Project for Youth Scholar (\#201372304010832), and the Fundamental Research Funds for the Central Universities (\#CCNU14A05046).

\section{REFERENCES}

Boman IA, Klemetsdal G, Blichfeldt T, Nafstad O, et al. (2009). A frameshift mutation in the coding region of the myostatin gene (MSTN) affects carcass conformation and fatness in Norwegian white sheep (Ovis aries). Anim. Genet. 40: 418-422.

Cao XJ, Wang WM and Song F (2011). Anatomical and histological characteristics of the intestine of the topmouth Culter (Culter alburnus). Anat. Histol. Embryol. 40: 292-298.

Fontanesi L, Scotti E, Frabetti A, Fornasini D, et al. (2011). Identification of polymorphisms in the rabbit (Oryctolagus cuniculus) myostatin (MSTN) gene and association analysis with finishing weight in a commercial rabbit population. Anim. Genet. 42: 339.

Guo L, Li L, Zhang S, Guo X, et al. (2011). Novel polymorphisms in the myostatin gene and their association with growth traits in a variety of bay scallop, Argopecten irradians. Anim. Genet. 42: 339-340.

Hayes B, Baranski M, Goddard ME and Robinson N (2007). Optimization of marker assisted selection for abalone breeding programs. Aquaculture 265: 61-69.

He F, Wen HS, Dong SL, Shi B, et al. (2008). Identification of single nucleotide polymorphism cytochrome P450-c19a and its relation to reproductive traits in Japanese flounder (Paralichthys olivaceus). Aquaculture 279: 177-181.

He XP, Xia JH, Wang CM, Pang HY, et al. (2011). Significant associations of polymorphisms in the prolactin gene with growth traits in Asian seabass (Lates calcarifer). Anim. Genet. 43: 233-236.

Lei M, Luo C, Peng C, Fang M, et al. (2007). Polymorphism of growth-correlated genes associated with fatness and muscle fiber traits in chickens. Poult. Sci. 86: 835-842.

Liu LS, Yu XM and Tong JG (2012). Molecular characterization of myostatin (MSTN) gene and association analysis with growth traits in the bighead carp (Aristichthys nobilis). Mol. Biol. Rep. 39: 9211-9221.

McPherron AC, Lawler AM and Lee SJ (1997). Regulation of skeletal muscle mass in mice by a new TGF-beta superfamily 
member. Nature 387: 83-90.

Tang YK, Li JL, Yu JH, Chen XF, et al. (2010). Genetic structure of MSTN and association between its polymorphisms and growth traits in genetically improved farmed tilapia (GIFT). J. Fish. Sci. China 17: 44-51.

Tao WJ and Boulding EG (2003). Associations between single nucleotide polymorphisms in candidate genes and growth rate in Arctic charr (Salvelinus alpinus L.). Heredity 91: 60-69.

Wang XL, Meng XY, Song B, Qiu XM, et al. (2010). SNPs in the myostatin gene of the mollusk Chlamys farreri: Association with growth traits. Comp. Biochem. Physiol. B 155: 327-330.

Xiong M, Qiao Y, Rosenthal H, Que Y, et al. (2006). Early ontogeny of Ancherythroculter nigrocauda and effects of delayed first feeding on larvae. J. Appl. Ichthyol. 22: 502-509.

Yu L, Tang H, Wang J, Wu Y, et al. (2007). Polymorphisms in the 5' regulatory region of myostatin gene are associated with early growth traits in Yorkshire pigs. Sci. China C Life Sci. 50: 642-647.

Zhang GX, Zhao XH, Wang JY, Ding FX, et al. (2011). Effect of an exon 1 mutation in the myostatin gene on the growth traits of the Bian chicken. Anim. Genet. 43: 458-459. 